\title{
O sistema de precedentes vinculantes e o incremento da eficiência na prestação jurisdicional: aplicar a ratio decidendi sem rediscuti-la
}

\author{
The system of binding precedents and the increase of efficiency in Justice making: applying \\ ratio decidendi without new deliberations about its contents
}

Frederico Augusto Leopoldino Koehler ${ }^{1}$

'Universidade Federal de Pernambuco - UFPE, Brasil

\begin{abstract}
Resumo
O presente artigo analisa como o sistema de precedentes vinculantes pode tornar o processo civil brasileiro mais racional, resultando em uma prestação jurisdicional mais eficiente. Isso decorrerá da simplificação do ônus argumentativo do juiz ao transpor para o caso concreto a ratio decidendi contida no precedente. Com isso, economiza-se o tempo que o magistrado perderia enfrentando novamente toda a argumentação jurídica que já fora apreciada no momento de formação do precedente, o que será especialmente útil nas
\end{abstract} demandas de massa.

Palavras-chave: Direito Processual Civil. CPC/2015. Precedentes obrigatórios. Motivação. Eficiência. Razoável duração do processo.

\begin{abstract}
The present article analyzes how a system of binding precedents can make the Civil Procedure in Brazil more rational, resulting in a more efficient Justice making. This will come from the simplification of the argumentative burden of the judge when applying the ratio decidendi of the precedent in a particular case. In this way, judges will save time they would otherwise lose facing the same legal reasoning that has already been defined and consolidated in the construction of the precedent, which will be specially helpful in repetitive claims.
\end{abstract}

Keywords: Civil Procedure. New Brazilian Code of Civil Procedure. Binding precedents. Reasons for judgment. Efficiency. Reasonable duration of the process.

\section{Introdução}

Com a entrada em vigor do NCPC, surgem vários questionamentos da comunidade jurídica, especialmente sobre sua real contribuição para uma maior efetividade da prestação jurisdicional e para que a tramitação dos processos se dê em prazo razoável, cumprindo-se, afinal, a determinação do art. $5^{\underline{o}}$, inc. LXXVIII, da Constituição Federal.

O presente artigo visa a analisar o impacto positivo que o sistema de precedentes vinculantes pode trazer para o processo civil brasileiro. O foco será a análise do momento de aplicação dos precedentes - não o de sua formação -, a fim de aferir se há algum aumento de eficiência derivado dessa nova sistemática.

Procederemos a uma análise, portanto, de como a fundamentação da decisão, nos casos de aplicação de precedente obrigatório, difere da motivação elaborada em um processo em que não haja a vinculação a precedente, e como isso irá impactar o trabalho cotidiano dos magistrados brasileiros. 


\section{A fundamentação das decisões judiciais no CPC/2015 (o art. 489, §1)}

A questão que se coloca nesse artigo é a seguinte: a prolatação de uma decisão judicial baseada em precedente obrigatório exige o mesmo nível de fundamentação de uma decisão que não esteja aplicando um precedente dessa natureza?

Formulando de outra maneira: ao transpor para um caso concreto a ratio decidendi contida no precedente, deve o magistrado enfrentar a argumentação jurídica que já fora apreciada no momento de sua formação?

Vejamos.

O art. 489, §1º, do CPC/2015, prescreve:

“\$ $1^{\circ}$ Não se considera fundamentada qualquer decisão judicial, seja ela interlocutória, sentença ou acórdão, que:

I - se limitar à indicação, à reprodução ou à paráfrase de ato normativo, sem explicar sua relação com a causa ou a questão decidida;

II - empregar conceitos jurídicos indeterminados, sem explicar o motivo concreto de sua incidência no caso;

III - invocar motivos que se prestariam a justificar qualquer outra decisão;

$I V$ - não enfrentar todos os argumentos deduzidos no processo capazes de, em tese, infirmar a conclusão adotada pelo julgador;

$V$ - se limitar a invocar precedente ou enunciado de súmula, sem identificar seus fundamentos determinantes nem demonstrar que o caso sob julgamento se ajusta àqueles fundamentos;

VI - deixar de seguir enunciado de súmula, jurisprudência ou precedente invocado pela parte, sem demonstrar a existência de distinção no caso em julgamento ou a superação do entendimento."

Como se vê, houve uma enorme preocupação do legislador em explicitar, de forma detalhada, os equívocos que uma decisão judicial não deve cometer, sob pena de considerar-se não fundamentada e, portanto, nula, com base no art. 93, inc. IX, da CF/1988 e no art. 11 do CPC/2015.

Boa parte da magistratura nacional receia que o dispositivo transcrito traga mais demora à tramitação dos feitos, na medida em que exigirá um maior trabalho de fundamentação, acompanhado de um possível aumento da oposição de embargos declaratórios'. É o que demonstra o teor de alguns dos enunciados aprovados no seminário "O Poder Judiciário e o novo CPC", realizado pela ENFAM - Escola Nacional de Formação e Aperfeiçoamento de Magistrados?: "Enunciado 47: "O art. 489 do CPC/2015 não se aplica ao sistema de juizados especiais"; Enunciado 9: "É ônus da parte, para os fins do disposto no art. 489, § 1 $1^{\circ}$, V e VI, do CPC/2015, identificar os fundamentos determinantes ou demonstrar a existência de distinção no caso em julgamento ou a superação do entendimento, sempre que invocar jurisprudência, precedente ou enunciado de súmula"; Enunciado 12: "Não ofende a norma extraível do inciso IV do $\S 1^{\circ}$ do art. 489 do CPC/2015 a decisão que deixar de apreciar questões cujo exame tenha ficado prejudicado em razão da análise anterior de questão subordinante".

Entendemos, contudo, que tal receio não se justifica.

$\mathrm{O}$ art. 489, §1º, do CPC/2015, na verdade, apenas esmiuça os deveres de fundamentação que todo magistrado já deveria ter sob a égide do CPC/1973. O inc. IV - de longe, o que mais polêmica tem gerado -, que prevê a nulidade para a decisão que "não enfrentar todos os argumentos deduzidos no processo capazes de, em tese, infirmar a conclusão adotada pelo julgador", nada inova em relação à sistemática do CPC/1973, uma vez que o magistrado jamais poderia deixar de enfrentar um argumento capaz de infirmar a conclusão da sua decisão.

1 Defendendo a inaplicabilidade do art. 489, $\$ 1^{\circ}$, ao sistema dos juizados especiais, confira-se: OLIVEIRA, Eduardo Perez. O dever de motivação das sentenças no Novo CPC - impacto no microssistema dos juizados especiais (cíveis, federais e da Fazenda Pública). In GAJARDONI, Fernando (coord.). Magistratura. Coleção Repercussões do Novo CPC, vol. 1. Salvador: Juspodivm, 2015, p. 101-103.

2 A ENFAM - Escola Nacional de Formação e Aperfeiçoamento de Magistrados promoveu o seminário "O Poder Judiciário e o novo CPC", com a participação de cerca de 500 juízes estaduais e federais de todo o país, no período de 26 a 28 de agosto de 2015, em que foram aprovados 62 enunciados interpretativos sobre o NCPC. O quórum de aprovação era de 2/3 (dois terços) dos participantes. 


\section{A fundamentação das decisões judiciais com base em precedentes obrigatórios}

Avançando para responder à pergunta central do presente artigo, podemos afirmar: não há sentido em obrigar que, no instante em que aplica o precedente vinculante, o juiz novamente - e sempre - tenha que (re)enfrentar toda a argumentação jurídica que já fora apreciada no momento de formação do precedente.

O enunciado 524 do Fórum Permanente de Processualistas Civis - FPPC dispõe exatamente nesse sentido": "O art. 489, $\$ 1^{\circ}$, IV, não obriga o órgão julgador a enfrentar os fundamentos jurídicos deduzidos no processo e já enfrentados na formação da decisão paradigma, sendo necessário demonstrar a correlação fática e jurídica entre o caso concreto e aquele já apreciado".

O enunciado 13 da ENFAM segue a mesma senda: "O art. 489, § $1^{\circ}, I V$, do CPC/2015 não obriga o juiz a enfrentar os fundamentos jurídicos invocados pela parte, quando já tenham sido enfrentados na formação dos precedentes obrigatórios".

Fique bem claro, no entanto, que não se está defendendo que o funcionamento de um sistema de precedentes seja menos complexo do que o sistema atual. Pelo contrário, os cuidados necessários na formação e na aplicação dos precedentes são inúmeros.

Defende-se, isto sim, que, em um sistema abarrotado de demandas repetitivas e de conflitos de massa, o ganho operacional em virtude da aplicação do sistema de precedentes é inegável. Poupa-se retrabalho em todos os processos em que o juiz teria que reforçar a argumentação já enfrentada e esgotada pela corte superior.

Importante a lição de Marinoni, de que é imprescindível justificar-se sempre a aplicação de um precedente, impondo-se identificar a ratio decidendi, isto é, os fundamentos determinantes do precedente que se deseja aplicar, bem como os fatos subjacentes no precedente, a fim de verificar-se a correlação fática e jurídica entre o paradigma e o caso concreto ${ }^{4}$.

Corroborando o afirmando, colhe-se o enunciado 19 da ENFAM: "A decisão que aplica a tese jurídica firmada em julgamento de casos repetitivos não precisa enfrentar os fundamentos já analisados na decisão paradigma, sendo suficiente, para fins de atendimento das exigências constantes no art. 489, § $1^{\circ}$, do CPC/2015, a correlação fática e jurídica entre o caso concreto e aquele apreciado no incidente de solução concentrada".

Note-se que examinar a correlação fática e jurídica do caso concreto nem sempre é tarefa fácil, pois cada processo singular possui peculiaridades e ostenta situações diferenciadas. Porém, um campo onde esse mister é facilitado é o das demandas de massa, as quais, via de regra, tratam de situações idênticas e de fácil cotejo com o paradigma.

Perceba-se que o art. 489, §1 $1^{\circ}$, inc. V, do CPC/2015 visa a combater a prática das pseudofundamentações, isto é, das decisões que, a pretexto de analisarem as razões que ensejaram a aplicação dos precedentes, limitam-se a mencionar apenas ementas de julgados ou de enunciados de súmulas, sem fazer a imprescindível correlação fática e jurídica do caso paradigma com o caso concreto ${ }^{5}$.

Quando o precedente vinculante é aplicado de forma tecnicamente correta, o julgamento torna-se mais rápido, sendo até mesmo possível que seja feito por decisão monocrática do relator, conforme previsto

3 O FPPC - Fórum Permanente de Processualistas Civis consiste em um encontro semestral (a partir de 2016 será anual) que conta com a participação de professores de processo de várias carreiras jurídicas (no último encontro, em Curitiba, estiveram presentes mais de 300 participantes de todo o país), e que tem como objetivo a elaboração de enunciados interpretativos sobre o NCPC. Para aprovação de um enunciado, exige-se a concordância da unanimidade dos participantes.

4 MARINONI, Luiz Guilherme. Comentários ao art. 926 do CPC/2015. In WAMBIER, Teresa Arruda Alvim et all (Coords.). Breves comentários ao novo Código de Processo Civil. São Paulo: Revista dos Tribunais, 2015, p. 2077.

5 CAMBI, Eduardo; HELlMAN, Renê Francisco. Os precedentes e o dever de motivação no Novo Código de Processo Civil. In: DIDIER JR., Fredie; CUNHA, Leonardo Carneiro da; ATAÍDE JR., Jaldemiro Rodrigues de; MACÊDO, Lucas Buril de. Precedentes. Coleção Grandes Temas do Novo CPC, vol. 3. Salvador: Juspodivm, 2015, p. 654. 
no art. 932, inc. IV e V do CPC/2015 . Gustavo Nogueira fornece o relato de Benjamin Cardozo, Juiz da Suprema Corte dos Estados Unidos da América entre 1932 e 1938, de que o trabalho dos juízes seria imensamente maior caso não pudessem assentar suas decisões em precedentes em que já houve discussão exaustiva dos argumentos pertinentes à causa ${ }^{7}$.

Como visto, a aplicação da tese firmada em precedente vinculante (a exemplo do julgamento de casos repetitivos $^{8}$ ) retira a necessidade de argumentação complementar em relação aos fundamentos que formam a ratio decidendi. É por isso que o CPC/2015 cria os princípios da comparticipação, coerência, integridade, estabilidade e da busca do resgate da efetiva colegialidade na formação do precedente, para, com esta medida, evitar-se o retrabalho no momento de sua aplicação. O cuidado na formação do precedente evita reanálises dos tribunais, como ocorre atualmente, em que constantemente se impõe o exame de argumentos negligenciados no momento de formação da ratio decidendi ${ }^{9}$. Ou seja, um precedente formado às pressas, sem a atenção devida e sem o respeito ao contraditório ampliado, não terá esse efeito positivo de redução do retrabalho no momento de aplicação da ratio decidendi.

De fato, motivação é o núcleo forte do sistema de precedentes - até porque é nela que reside a ratio decidendi - o que impõe maior qualidade no momento da elaboração dos precedentes ${ }^{10}$.

Daí a grande relevância de se distinguir um sistema de precedentes funcionando corretamente de um mero sistema de elaboração e aplicação de enunciados de súmulas, tal como ocorreu até hoje no processo brasileiro. Não se pode olvidar que, por mais que se tente esgotar a discussão a partir de um enunciado de súmula, o fato é que este é um texto e, como tal, possui o mesmo pathos da lei: estão sempre sujeitos à interpretação no momento de aplicação ${ }^{11}$.

A aplicação de um precedente não consiste em uma operação subsuntiva com uma submissão mecânica e cega. Não se dispensa, por óbvio, algum grau de interpretação para a aplicação do acórdão paradigma. Lênio Streck e Georges Abboud alertam sobre os perigos de uma aplicação dos precedentes de forma dedutiva-subsuntiva-mecânica, como um silogismo, e alertando ser indispensável - e inescapável -, também nesses casos, a intepretação por parte do julgador. As decisões que utilizarão como base a ratio decidendi de um precedente vinculante não serão frutos de silogismo. Pelo contrário, elas também constituem atos hermenêuticos ${ }^{12}$.

6 "Art. 932. Incumbe ao relator:

(...).

$I V$ - negar provimento a recurso que for contrário a:

a) súmula do Supremo Tribunal Federal, do Superior Tribunal de Justiça ou do próprio tribunal;

b) acórdão proferido pelo Supremo Tribunal Federal ou pelo Superior Tribunal de Justiça em julgamento de recursos repetitivos;

c) entendimento firmado em incidente de resolução de demandas repetitivas ou de assunção de competência;

$V$ - depois de facultada a apresentação de contrarrazões, dar provimento ao recurso se a decisão recorrida for contrária a:

a) súmula do Supremo Tribunal Federal, do Superior Tribunal de Justiça ou do próprio tribunal;

b) acórdão proferido pelo Supremo Tribunal Federal ou pelo Superior Tribunal de Justiça em julgamento de recursos repetitivos;

c) entendimento firmado em incidente de resolução de demandas repetitivas ou de assunção de competência;"

7 NOGUEIRA, Gustavo Santana. Precedentes vinculantes no direito comparado e brasileiros. 2. ed. Salvador: Juspodivm, 2015, p. 89.

8 Conforme o art. 928, a expressão "julgamento de casos repetitivos" abrange os recursos extraordinários e especiais julgados em regime de recursos repetitivos e o julgamento do incidente de resolução de demandas repetitivas - IRDR.

9 THEODORO JÚNIOR, Humberto; NUNES, Dierle; BAHIA, Alexandre Franco Melo; PEDRON, Flávio Quinaud. Novo CPC: fundamentos e sistematização. Rio de Janeiro: Forense, 2015, p. 298.

10 DIDIER JR., Fredie; BRAGA, Paula Sarno; OLIVEIRA, Rafael Alexandria de. Curso de Direito Processual Civil: teoria da prova, direito probatório, decisão, precedente, coisa julgada e tutela provisória. Vol. 2. 10. ed. Salvador: Juspodivm, 2015 , p. 470.

11 ThEODORO JÚNIOR, Humberto; NUNES, Dierle; BAHIA, Alexandre Franco Melo; PEDRON, Flávio Quinaud. Novo CPC: fundamentos e sistematização. Rio de Janeiro: Forense, 2015, p. 298.

12 STRECK, Lênio; ABBOUD, Georges. O NCPC e os precedentes - afinal, do que estamos falando. In: DIDIER JR., Fredie; CUNHA, Leonardo Carneiro da; ATAÍDE JR., Jaldemiro Rodrigues de; MACÊDO, Lucas Buril de. Precedentes. Coleção Grandes Temas do Novo CPC, vol. 3. Salvador: Juspodivm, 2015, p. 175-182. Com a mesma preocupação, confirase: SEDLACEK, Federico D. Misceláneas argentinas del precedente judicial, y su relación con el nuevo CPC de Brasil. In: DIDIER JR., Fredie; CUNHA, Leonardo Carneiro da; ATAÍDE JR., Jaldemiro Rodrigues de; MACÊDO, Lucas Buril de. Precedentes. Coleção Grandes Temas do Novo CPC, vol. 3. Salvador: Juspodivm, 2015, p. 380-381. 
Há que se ter sempre o cuidado de não se utilizar os precedentes de forma irrefletida, isto é, sem que se faça a comparação dos fatos do caso concreto com a situação fática que compõe a ratio decidendi. Viola a igualdade o comportamento do tribunal que aplica um precedente a uma situação substancialmente distinta daquela que gerou a ratio decidendi. Por isso o NCPC prevê a técnica da distinção (arts. 489, $\S 1^{\circ}$, V e VI, e $927, \S 1^{1}$ ), por meio da qual o julgador deve verificar se há similitude fática entre o caso paradigma e o caso em julgamento, de modo a fazer incidir ou não a ratio decidendi. Deve o julgador delinear, também, e de forma explícita, a tese jurídica adotada para se chegar à conclusão exposta na parte dispositiva. Isso para que as partes possam submeter a aplicação da ratio decidendi a eventual controle recursal ${ }^{13}$.

Logo, não se afirma aqui que o magistrado deva seguir os precedentes de forma acrítica. Apesar da possibilidade de uma fundamentação mais concisa nesse caso, tal fato não exime o magistrado de, como dito acima, comprovar a a correlação fática e jurídica entre o caso concreto e aquele apreciado no processo paradigma. Em verificando não existir essa correlação fática e jurídica, deverá o julgador operar a distinção, desvinculando a solução do caso concreto daquela solução obtida no precedente.

Nesse sentido dispõem o enunciado 306 do FPPC: “O precedente vinculante não será seguido quando o juiz ou tribunal distinguir o caso sob julgamento, demonstrando, fundamentadamente, tratar-se de situação particularizada por hipótese fática distinta, a impor solução jurídica diversa" e o enunciado 20 da ENFAM: "O pedido fundado em tese aprovada em IRDR deverá ser julgado procedente, respeitados o contraditório e a ampla defesa, salvo se for o caso de distinção ou se houver superação do entendimento pelo tribunal competente".

Sobre o tema, pede-se vênia para transcrever um trecho esclarecedor de artigo de Dierle Nunes ${ }^{14}$ :

\begin{abstract}
"Julgar melhor para julgar menos à medida que um precedente que aborde todos os fundamentos, favoráveis ou contrários (dever de consideração: artigo 489, \$1 em audiências públicas e respeito a um dever de congruência entre o que se fixou para julgamento e o que se efetivamente julgou, poderá induzir uma efetiva redução do retrabalho e, inclusive, diminuição da litigiosidade pela existência de uma verdadeira opinião da corte sobre o caso, de modo a se assegurar uma jurisprudência coerente, integra e estável (artigo 926).

Este precedente serviria como fundamento de julgamento (artigo 489, \$1 ${ }^{\circ}$, V e VI) em: a) julgamentos liminares de improcedência (artigo 332); b) tutelas antecipadas da evidência (artigo 311, II); c) decisões monocráticas (artigo 932 , IV e V); d) resolução de conflitos de competência (artigo 955, parágrafo único, I e II); e) obtenção de executividade imediata de sentenças (artigo 1.012, V); f) impedimento de reexame necessário (artigo 496, \$4ª , II). Não se olvidando de potenciais funções rescindentes (artigos 525, \$15 e 535, \$\$5ํo $8^{\circ}$ ).” (grifou-se)
\end{abstract}

Como visto, há inúmeras situações processuais - como o julgamento liminar de improcedência (artigo 332), a tutela antecipada de evidência (artigo 311, inc. II), e as decisões monocráticas (artigo 932, inc. IV e V) - em que a existência de precedentes vinculantes poderá abreviar o trâmite processual e tornar a jurisdição mais eficiente.

No que tange ao julgamento liminar de improcedência do pedido, por exemplo, é permitida a sua aplicação desde que embasada na existência de precedentes vinculantes, e desde que não seja necessária a produção de provas sobre os fatos alegados pelo autor, o que resultará na prolatação imediata da sentença, com a dispensa da citação do réu ${ }^{15}$.

Fenômeno análogo ocorrerá com o julgamento de demandas de massa embasadas em um precedente formado no âmbito do incidente de resolução de demandas repetitivas - IRDR, o que deverá contribuir para a razoável duração dos processos. Ojuiz, com respaldo no precedente, irá transpor ao julgamento do caso concreto a razão de decidir já assentada, podendo: a) julgar a demanda liminarmente improcedente,

13 DIDIER JR., Fredie; BRAGA, Paula Sarno; OLIVEIRA, Rafael Alexandria de. Curso de Direito Processual Civil: teoria da prova, direito probatório, decisão, precedente, coisa julgada e tutela provisória. Vol. 2. 10. ed. Salvador: Juspodivm, 2015 , p. 469 e 471.

14 NUNES, Dierle. Proposta de reforma do novo Código de Processo Civil apresenta riscos. Revista Consultor Jurídico, 26 de novembro de 2015. Disponível em: <http://www.conjur.com.br/2015-nov-26/dierle-nunes-proposta-reforma-cpcapresenta-riscos>. Acesso em: 03 fev. 2016.

15 CAVALCANTI, Marcos de Araújo. O incidente e resolução de demandas repetitivas e as ações coletivas. Salvador: Juspodivm, 2015 , p. 469. 
com base no art. 332, inc. III, do CPC/2015; ou b) conceder liminarmente a tutela de evidência, com espeque no art. 311, inc. II, quando as alegações de fato puderem ser comprovadas integralmente pela via documental. Tal sistemática, como se nota, abreviará a resolução do process ${ }^{16}$. A propósito, o enunciado 31 da ENFAM propõe que: "A concessão da tutela de evidência prevista no art. 311, II, do CPC/2015 independe do trânsito em julgado da decisão paradigma".

A aplicação dos precedentes vinculantes também contribui para combater uma péssima praxe solidificada em nosso direito, qual seja, a coexistência de julgamentos díspares para situações idênticas, em afronta à igualdade, imparcialidade e à segurança jurídica. De fato, o Poder Judiciário não pode ser reduzido à soma dos valores e opiniões individuais de seus membros, não se podendo olvidar que os juízes e tribunais fazem parte de um só sistema e Poder, o que caracteriza o aspecto institucional das decisões judiciais. O juiz não está submetido apenas à lei em abstrato, mas também à norma jurídica que os tribunais extraem da lei ao interpretá-la ${ }^{17}$.

O desafio do momento é a superação do individualismo nas decisões judiciais, avançando-se para um modelo mais institucionalista, obedecendo-se ao dever de autorreferência, ou seja, de um maior respeito aos precedentes. Só isso permitirá que os litigantes sejam tratados de forma isonômica, com maior previsibilidade e segurança jurídica ${ }^{18}$.

O solipsismo (julgamento autocentrado, sem observância à doutrina e à jurisprudência), o panprincipiologismo (uso exacerbado de princípios, sem a fundamentação adequada) e o sistemático desrespeito aos precedentes, no Brasil, tem comprometido o próprio Estado de Direito, na medida em que as coisas passam a ocorrer como se houvesse várias leis regendo a mesma conduta, o que gera um clima de insegurança jurídica e ausência de previsibilidade ${ }^{19}$. Esse estado de coisas é o que Eduardo Cambi chamou de jurisprudência lotérica ${ }^{20}$.

A jurisprudência lotérica afronta a coerência jurídica e a integridade do Direito, e deslegitima a prestação jurisdicional, uma vez que as normas são aplicadas de maneira diferente para casos similares. A isonomia só será cumprida quando situações análogas forem decididas da mesma maneira. Caso contrário, teremos imprevisibilidade, instabilidade e dificuldade do cidadão em saber como se portar em suas relações jurídicas ${ }^{21}$.

Os precedentes não são formados tão somente para a solução do caso concreto, mas sim de todos os casos em situação análoga, conferindo a todo o sistema, assim, um controle de racionalidade decorrente da regra de universalizaçã $0^{22}$. $\mathrm{O}$ afastamento da regra de universalização deve ser feito apenas excepcionalmente, e tem que ser fortemente justificado.

Aí que entra a ideia de uma argumentação qualificada, uma espécie de ônus argumentativo do órgão julgador para quando seja o caso de se apartar do precedente. Tal ônus não está presente quando seja o caso de seguir o precedente, hipótese em que a tarefa de fundamentação estará facilitada.

16 STEINBERG, José Fernando. Impacto do NCPC na uniformização de jurisprudência nos juizados especiais. $I n$ : REDONDO, Bruno Garcia; SANTOS, Welder Queiroz dos; SILVA, Augusto Vinícius Fonseca e; VALLADARES, Leandro Carlos Pereira. Juizados Especiais. Coleção Repercussões do Novo CPC, vol. 7. Salvador: Juspodivm, 2015 , p. 563.

17 MARINONI, Luiz Guilherme. Comentários ao art. 926 do CPC/2015. In WAMBIER, Teresa Arruda Alvim et all (Coords.). Breves comentários ao novo Código de Processo Civil. São Paulo: Revista dos Tribunais, 2015, p. 2073.

18 PEIXOTO, Ravi. A recepção legislativa e o stare decisis - um breve estudo dos desafios rumo ao desenvolvimento de uma teoria brasileira dos precedentes a partir do CPC/2015. In: SANTANA, Alexandre Ávalo; ANDRADE NETO, José de (coord.). Novo CPC: análise doutrinária sobre o novo direito processual brasileiro, vol. 3. Campo Grande: Contemplar: 2016, p. 311.

19 ATAÍDE JR., Jaldemiro Rodrigues. Precedentes e fundamentação no NCPC. In: SANTANA, Alexandre Ávalo; ANDRADE NETO, José de (coord.). Novo CPC: análise doutrinária sobre o novo direito processual brasileiro, vol. 3. Campo Grande: Contemplar: 2016, p. 323.

20 CAMBI, Eduardo. Jurisprudência lotérica. RT 78/108-128. São Paulo: Revista dos Tribunais, abr. 2001 , p. 111.

21 CAMBI, Eduardo; MARGRAF, Alencar Frederico. Casuísmos judiciários e precedentes judiciais. In: SANTANA, Alexandre Ávalo; ANDRADE NETO, José de (coord.). Novo CPC: análise doutrinária sobre o novo direito processual brasileiro, vol. 3. Campo Grande: Contemplar: 2016, p. 363.

22 ZANETIJR., Hermes. O valor vinculante dos precedentes. Salvador: Juspodivm, 2015, p. 353. 
Chaim Perelman leciona sobre o princípio da inércia, segundo o qual um precedente somente pode ser modificado se existirem razões suficientes, pesando em seu favor o ônus argumentativo. O princípio da inércia não é a principal justificação racional para o sistema de precedentes, cabendo tal lugar de destaque à regra de universalização, acima mencionada. A inércia vale apenas como ônus argumentativo, ou seja, a presunção a favor dos precedentes ${ }^{23}$.

O princípio da inércia argumentativa é concretizado art. 489, \$1º, incisos V e VI, do CPC/2015, cujo conteúdo consiste em dispensar de uma ampla argumentação o magistrado que, no julgamento de caso posterior, segue precedente firmado em caso análogo. Por outro lado, exige-se uma carga argumentativa qualificada ao magistrado que pretenda se afastar da ratio decidendi de precedente aplicável ao caso em julgamento. Exige-se do julgador uma fundamentação qualificada, com pesado ônus argumentativo, do qual se desincumbirá apenas se demonstrar superação (overruling) do precedente - o que só poderá ser feito pelo tribunal que formou o precedente ou por tribunal superior - ou a distinção (distinguishing) ${ }^{24}$.

O juiz pode - e isso é desejável, sempre que possível - acrescentar novos argumentos para seguir o precedente, mas não desafiá-lo em sua ratio decidendi. As partes podem trazer argumentos novos na tentativa de superar o precedente - e isso costuma acontecer bastante nas demandas de massa - mas quem terá de enfrentá-los é somente e, se for o caso, o tribunal que criou o precedente. A superação, repitase, só pode ser feita por quem criou o precedente ou por tribunal superior. O papel mais importante, nos casos de aplicação de precedentes, é verificar se é ou não o caso de distinção, essa sim uma atribuição de todos os magistrados que julgarem o feito, mesmo que não componham o órgão responsável pela formação do precedente ${ }^{25}$.

Portanto, a obrigatoriedade de obediência ao precedente isenta o juiz de responsabilidade pelo teor da decisão paradigma. O julgador, ao aplicar o precedente, pode, justificadamente, diminuir a carga de argumentação jurídica empregada no caso concreto. Como diz Frederick Schauer, o produto líquido disso será uma redução substancial no esforço decisório, e é precisamente aí que a eficiência pode justificar a adoção de um sistema de precedentes vinculantes ${ }^{26}$.

Além de evitar o retrabalho, a aplicação da ratio decidendi dos precedentes vinculantes possui, ainda, um outro fator positivo. Isso porque o costume atual dos tribunais, de sempre reenfrentar a mesma questão jurídica, leva a frequentes mudanças de entendimento, até pela tentação de cada novo julgador querer reexaminar a questão com sua própria ideologia ${ }^{27}$.

Note-se que o juiz, embora não esteja autorizado a realizar a superação, poderá, sem sombra de dúvidas, influenciar a corte formadora do precedente por meio da técnica de ressalva de entendimento. Tal técnica consiste em curvar-se ao posicionamento cristalizado no precedente sem abrir mão de argumentar de acordo com o ponto de vista contrário, possibilitando ao tribunal, no momento adequado, realizar eventual superação.

23 ZANETI JR., Hermes. O valor vinculante dos precedentes. Salvador: Juspodivm, 2015, p. 357.

24 ATAÍDE JR., Jaldemiro Rodrigues de. Precedentes e fundamentação no NCPC. In: SANTANA, Alexandre Ávalo; ANDRADE NETO, José de (coord.). Novo CPC: análise doutrinária sobre o novo direito processual brasileiro, vol. 3. Campo Grande: Contemplar: 2016, p. 345.

25 Nesse sentido, confira-se: GOUVEIA, Lúcio Grassi de; BREITENBACH, Fábio Gabriel. Sistema de precedentes no novo Código de Processo Civil brasileiro: um passo para o enfraquecimento da jurisprudência lotérica dos tribunais. In: DIDIER JR., Fredie; CUNHA, Leonardo Carneiro da; ATAÍDE JR., Jaldemiro Rodrigues de; MACÊDO, Lucas Buril de. Precedentes. Coleção Grandes Temas do Novo CPC, vol. 3. Salvador: Juspodivm, 2015, p. 513; PEIXOTO, Ravi. Aspectos materiais e processuais da superação de precedentes no processo brasileiro. In: DIDIER JR., Fredie; CUNHA, Leonardo Carneiro da; ATAÍDE JR., Jaldemiro Rodrigues de; MACÊDO, Lucas Buril de. Precedentes. Coleção Grandes Temas do Novo CPC, vol. 3. Salvador: Juspodivm, 2015, p. 546.

26 SCHAUER, Frederick. Precedente. In: DIDIER JR., Fredie; CUNHA, Leonardo Carneiro da; ATAÍDE JR., Jaldemiro Rodrigues de; MACÊDO, Lucas Buril de. Precedentes. Coleção Grandes Temas do Novo CPC, vol. 3. Salvador: Juspodivm, 2015, p. 80 .

27 ATAÍDE JR., Jaldemiro Rodrigues de. Precedentes vinculantes e irretroatividade do direito no sistema processual brasileiro: os precedentes dos tribunais superiores e sua eficácia temporal. Curitiba: Juruá, 2012, p. 136-8. 
A propósito, colaciona-se o enunciado 172 do FPPC: "A decisão que aplica precedentes, com a ressalva de entendimento do julgador, não é contraditória".

Por fim, conclui-se que a paz social não se atinge por um utópico consenso em torno das decisões estatais, mas sim pela imunização contra os ataques dos contrariados, ou seja, os jurisdicionados precisam se conformar com a resposta dada pelo Poder Judiciário. Essa resignação se dá em virtude da obediência ao devido processo legal e à possibilidade de exaurimento de todas as instâncias, mesmo quando a decisão for contrária aos seus interesses imediatos ${ }^{28}$. A imunização, portanto, ocorre no momento da fixação do precedente vinculante, ocasião em que contraditório deve ser ampliado, de modo a permitir ampla participação da sociedade nesse instante fundamental. Não caberá, assim, a rediscussão do precedente em casos futuros, pois o litígio em questão já se encontra imunizado.

\section{Conclusão}

Conclui-se que o sistema de precedentes obrigatórios, se corretamente aplicado, representará, além da concretização da isonomia e de mais segurança jurídica na aplicação da norma - o que não foi o tema central deste ensaio -, uma prestação jurisdicional mais efetiva e uma redução no tempo de tramitação dos processos.

Isso decorrerá, como visto, da racionalização do ônus argumentativo do juiz no momento do julgamento, com a transposição para o caso concreto da ratio decidendi contida no precedente. Com isso, economizase o tempo que o magistrado perderia enfrentando novamente toda a argumentação jurídica que já fora apreciada no momento de formação do precedente.

Como doutrina Frederick Schauer, a subordinação aos precedentes acarreta uma padronização e uma estabilidade de decisões, e um consequente aumento da consistência interna do sistema jurisdicional, emprestando maior credibilidade ao Poder Judiciário, o que o fortalece como instituição ${ }^{29}$.

José Henrique Mouta Araújo, por sua vez, leciona que estamos diante de um caminho sem volta, qual seja, a otimização do tempo e das decisões dos tribunais, especialmente em matérias repetitivas, que geralmente envolvem litigantes habituais. A liberdade de criação dos juízes estará restringida nos casos análogos já julgados em precedentes vinculantes, estimulando-se a fundamentação per relationem. Há, neste sentido, a necessidade de ser repensado o próprio princípio da motivação judicial e, consequentemente, o papel do juiz e sua liberdade na criação e aplicação do direito ${ }^{30}$.

Estamos cientes, entretanto, de que o pleno funcionamento do sistema de precedentes no Brasil deve demorar alguns anos, até que se modifique a cultura atual de formação e aplicação da jurisprudência das cortes judiciárias em nosso país.

\section{Referências}

ARAÚJO, José Henrique Mouta. Os precedentes vinculantes e o Novo CPC: o futuro da liberdade interpretativa e do processo de criação do direito. In: DIDIER JR., Fredie; CUNHA, Leonardo Carneiro da; ATAÍDE JR., Jaldemiro Rodrigues de; MACÊDO, Lucas Buril de. Precedentes. Coleção Grandes Temas do Novo CPC, vol. 3. Salvador: Juspodivm, 2015, p. 425-443.

28 CAMBI, Eduardo; HELLMAN, Renê Francisco. Os precedentes e o dever de motivação no Novo Código de Processo Civil. In: DIDIER JR., Fredie; CUNHA, Leonardo Carneiro da; ATAÍDE JR., Jaldemiro Rodrigues de; MACÊDO, Lucas Buril de. Precedentes. Coleção Grandes Temas do Novo CPC, vol. 3. Salvador: Juspodivm, 2015, p. 654.

29 SCHAUER, Frederick. Precedente. In: DIDIER JR., Fredie; CUNHA, Leonardo Carneiro da; ATAÍDE JR., Jaldemiro Rodrigues de; MACÊDO, Lucas Buril de. Precedentes. Coleção Grandes Temas do Novo CPC, vol. 3. Salvador: Juspodivm, 2015, p. 81.

30 ARAÚJO, José Henrique Mouta. Os precedentes vinculantes e o Novo CPC: o futuro da liberdade interpretativa e do processo de criação do direito. In: DIDIER JR., Fredie; CUNHA, Leonardo Carneiro da; ATAÍDE JR., Jaldemiro Rodrigues de; MACÊDO, Lucas Buril de. Precedentes. Coleção Grandes Temas do Novo CPC, vol. 3. Salvador: Juspodivm, 2015, p. 431 e 435. 
ATAÍDE JR., Jaldemiro Rodrigues de. As demandas de massa e o projeto de novo Código de Processo Civil. In: FREIRE, Alexandre et al (org.). Novas Tendências do Processo Civil: estudos sobre o projeto do novo Código de Processo Civil. Vol. 3. Salvador: Juspodivm, 2014, p. 45-69.

. Precedentes vinculantes e irretroatividade do direito no sistema processual brasileiro: os precedentes dos tribunais superiores e sua eficácia temporal. Curitiba: Juruá, 2012.

Precedentes e fundamentação no NCPC. In: SANTANA, Alexandre Ávalo; ANDRADE

NETO, José de (coord.). Novo CPC: análise doutrinária sobre o novo direito processual brasileiro, vol.

3. Campo Grande: Contemplar: 2016, p. 319-347.

CAMBI, Eduardo. Jurisprudência lotérica. RT 78/108-128. São Paulo: Revista dos Tribunais, abr. 2001.

CAMBI, Eduardo; HELLMAN, Renê Francisco. Os precedentes e o dever de motivação no Novo Código de Processo Civil. In: DIDIER JR., Fredie; CUNHA, Leonardo Carneiro da; ATAÍDE JR., Jaldemiro Rodrigues de; MACÊDO, Lucas Buril de. Precedentes. Coleção Grandes Temas do Novo CPC, vol. 3. Salvador: Juspodivm, 2015, p. 633-658.

CAMBI, Eduardo; MARGRAF, Alencar Frederico. Casuísmos judiciários e precedentes judiciais. In: SANTANA, Alexandre Ávalo; ANDRADE NETO, José de (coord.). Novo CPC: análise doutrinária sobre o novo direito processual brasileiro, vol. 3. Campo Grande: Contemplar: 2016, p. 348-365.

CAVALCANTI, Marcos de Araújo. O incidente e resolução de demandas repetitivas e as ações coletivas. Salvador: Juspodivm, 2015.

DIDIER JR., Fredie; BRAGA, Paula Sarno; OLIVEIRA, Rafael Alexandria de. Curso de Direito Processual Civil: teoria da prova, direito probatório, decisão, precedente, coisa julgada e tutela provisória. Vol. 2. 10. ed. Salvador: Juspodivm, 2015.

Enunciados do Fórum Permanente de Processualistas Civis - FPPC. Disponível em: <http:// portalprocessual.com/wp-content/uploads/2015/12/Carta-de-Curitiba.pdf>. Acesso em: 03 fev. 2016.

Enunciados do Seminário "O Poder Judiciário e o Novo Código de Processo Civil", promovido pela Escola Nacional de Formação e Aperfeiçoamento de Magistrdos - ENFAM. Disponível em: <http://www.enfam.jus. $\mathrm{br}$ /wp-content/uploads/2015/09/ENUNCIADOS-VERS\%C3\%83O-DEFINITIVA-.pdf>. Acesso em: 03 fev. 2016.

GOUVEIA, Lúcio Grassi de; BREITENBACH, Fábio Gabriel. Sistema de precedentes no novo Código de Processo Civil brasileiro: um passo para o enfraquecimento da jurisprudência lotérica dos tribunais. In: DIDIER JR., Fredie; CUNHA, Leonardo Carneiro da; ATAIIDE JR., Jaldemiro Rodrigues de; MACÊDO, Lucas Buril de. Precedentes. Coleção Grandes Temas do Novo CPC, vol. 3. Salvador: Juspodivm, 2015, p. 491-519.

KOEHLER, Frederico Augusto Leopoldino. A razoável duração do processo. 2. ed. Salvador: Juspodivm, 2013.

MARINONI, Luiz Guilherme. Comentários ao art. 926 do CPC/2015. In WAMBIER, Teresa Arruda Alvim et all (Coords.). Breves comentários ao novo Código de Processo Civil. São Paulo: Revista dos Tribunais, 2015, p. 2072-2075.

NOGUEIRA, Gustavo Santana. Precedentes vinculantes no direito comparado e brasileiros. 2. ed. Salvador: Juspodivm, 2015.

NUNES, Dierle. Proposta de reforma do novo Código de Processo Civil apresenta riscos. Revista Consultor Jurídico, 26 de novembro de 2015. Disponível em: <http://www.conjur.com.br/2015-nov-26/ dierle-nunes-proposta-reforma-cpc-apresenta-riscos>. Acesso em: 03 fev. 2016.

OLIVEIRA, Eduardo Perez. O dever de motivação das sentenças no Novo CPC - impacto no microssistema dos juizados especiais (cíveis, federais e da Fazenda Pública). In GAJARDONI, Fernando (coord.). Magistratura. Coleção Repercussões do Novo CPC, vol. 1. Salvador: Juspodivm, 2015, p. 97-103. 
PEIXOTO, Ravi. A recepção legislativa e o stare decisis - um breve estudo dos desafios rumo ao desenvolvimento de uma teoria brasileira dos precedentes a partir do CPC/2015. In: SANTANA, Alexandre Ávalo; ANDRADE NETO, José de (coord.). Novo CPC: análise doutrinária sobre o novo direito processual brasileiro, vol. 3. Campo Grande: Contemplar: 2016, p. 297-318.

- Aspectos materiais e processuais da superação de precedentes no processo brasileiro. In: DIDIER JR., Fredie; CUNHA, Leonardo Carneiro da; ATAÍDE JR., Jaldemiro Rodrigues de; MACÊDO, Lucas Buril de. Precedentes. Coleção Grandes Temas do Novo CPC, vol. 3. Salvador: Juspodivm, 2015, p. 537-563.

ROSSI, Júlio César. O precedente à brasileira: súmula vinculante e incidente de resolução de demandas repetitivas. Revista de Processo, a. 37, v. 208, p. 203-240, jun. 2012.

SCHAUER, Frederick. Precedente. In: DIDIER JR., Fredie; CUNHA, Leonardo Carneiro da; ATAÍDE JR., Jaldemiro Rodrigues de; MACÊDO, Lucas Buril de. Precedentes. Coleção Grandes Temas do Novo CPC, vol. 3. Salvador: Juspodivm, 2015, p. 49-86.

SEDLACEK, Federico D. Misceláneas argentinas del precedente judicial, y su relación con el nuevo CPC de Brasil. In: DIDIER JR., Fredie; CUNHA, Leonardo Carneiro da; ATAÍDE JR., Jaldemiro Rodrigues de; MACÊDO, Lucas Buril de. Precedentes. Coleção Grandes Temas do Novo CPC, vol. 3. Salvador: Juspodivm, 2015, p. 361-381.

STEINBERG, José Fernando. Impacto do NCPC na uniformização de jurisprudência nos juizados especiais. In: REDONDO, Bruno Garcia; SANTOS, Welder Queiroz dos; SILVA, Augusto Vinícius Fonseca e; VALLADARES, Leandro Carlos Pereira. Juizados Especiais. Coleção Repercussões do Novo CPC, vol. 7. Salvador: Juspodivm, 2015, p. 557-571.

STRECK, Lênio; ABBOUD, Georges. O NCPC e os precedentes - afinal, do que estamos falando. In: DIDIER JR., Fredie; CUNHA, Leonardo Carneiro da; ATAÍDE JR., Jaldemiro Rodrigues de; MACÊDO, Lucas Buril de. Precedentes. Coleção Grandes Temas do Novo CPC, vol. 3. Salvador: Juspodivm, 2015, p. 175-182.

THEODORO JÚNIOR, Humberto; NUNES, Dierle; BAHIA, Alexandre Melo Franco; PEDRON, Flávio Quinaud. Novo CPC: fundamentos e sistematização. Rio de Janeiro: Forense, 2015.

ZANETI JR., Hermes. O valor vinculante dos precedentes. Salvador: Juspodivm, 2015 